\title{
THE EFFECT OF HIGH TEMPERATURE AIR EXPOSURE ON THE STRESS RUPTURE LIFE OF NICKEL AND COBALT BASE SUPERALLOYS
}

by

\author{
D. A. Woodford and R. H. Bricknell \\ General Electric Company \\ Corporate Research \& Development Center \\ Schenectady, New York
}

The effect of prior air exposure on rupture life of superalloys is reported. Oxygen is identified as a damaging species leading to severe losses in both rupture life and ductility. Similar embrittlement is observed in pure nickel and a mechanism is proposed in terms of reduced grain boundary mobility. Two cobalt base alloys and an oxide dispersion strengthened nickel base alloy do not embrittle in air. It is suggested that the cobalt alloys are immune to oxygen damage and the ODS alloy is intrinsically embrittled as processed.

\section{INTRODUCTION}

High temperature environmental embrittlement of nickel base superalloys has been observed(1-3), but is not widely recognized. The most detailed study reported the tensile properties of Rene'77, 80 and 100 after prior air exposures at $980^{\circ} \mathrm{C}(2)$. It was found that the alloys had been embrittled, and that this embrittlement was most pronounced in a narrow temperature range between $700^{\circ} \mathrm{C}$ and $900^{\circ} \mathrm{C}$. Because the three alloys studied formed a grain boundary $\gamma^{\prime}$ film on exposure, it was suggested that this was the embrittled phase, and a prerequisite for embrittlement. Further work, however, has demonstrated that $\gamma^{\prime}$ film formation is not necessary for embrittlement(3), but the mechanism of embrittlement, the gaseous species responsible, and the range of alloys affected remain to be elucidated.

In view of the reported severe degradation of at least one property of engineering importance, work was undertaken to explore further the embrittlement phenomenon relative to other properties. Some preliminary results had shown that stress rupture lives of cast superalloys could be significantly reduced by prior air exposure(4), 
and the present paper summarizes a more detailed study of the effect of air exposure on rupture lives of several nickel and cobalt base alloys.

Included in the present paper are some results obtained on pure nickel, which proved important in expanding our awareness of the generality of the embrittlement encountered, and in determining a possible mechanism.

\section{EXPERIMENTAL PROCEDURE}

The compositions and heat treatments used for the various alloys are given in Table 1. The cast alloys were poured in argon into $20 \mathrm{~mm} \times 60 \mathrm{~mm} \times 75 \mathrm{~mm}$ graphite molds; MA754 was obtained in the form of test blocks which had been thermomechanically processed to develop an aligned microstructure; and Ni270 was in the form of hot extruded rod. Specimen slugs were electro-discharge machined and ground to size with a reduced gage section of $9.53 \mathrm{~mm}$ and gage diameter of $2.54 \mathrm{~mm}$. Post exposure lives were measured for the superalloys at $700,800,900$ and $1000^{\circ} \mathrm{C}$ following air exposure at $1000^{\circ} \mathrm{C}$. For comparison, tests were also performed after exposure in flowing nitrogen or in vacuum after encapsulation at $10^{-5}$ torr. All rupture tests were conducted in air.

\section{TABLE 1}

\section{Composition and Processing of Alloys}

Composition (wt. $\%$ )

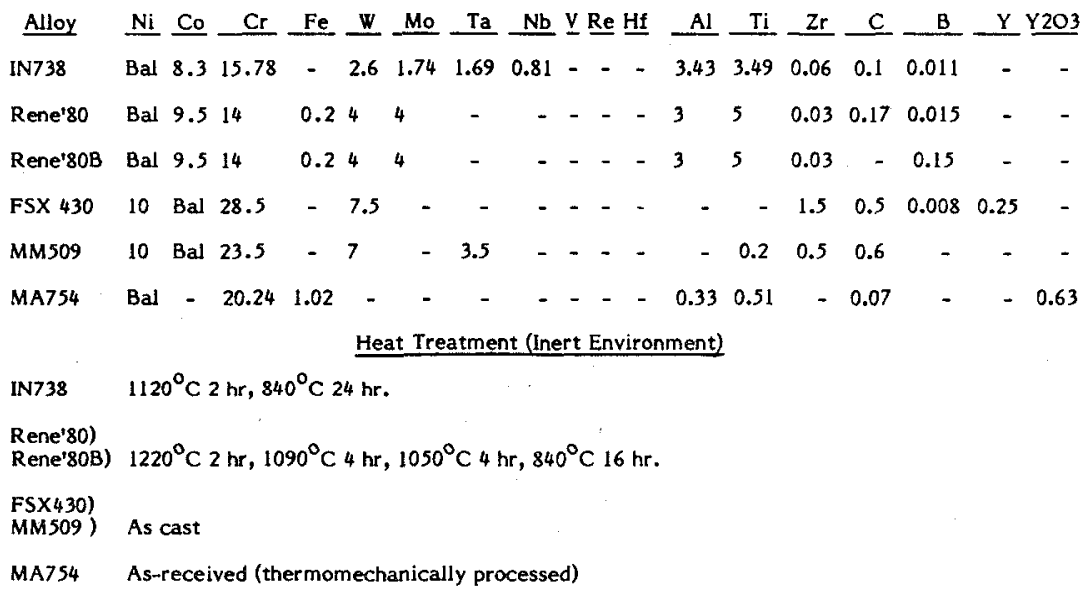




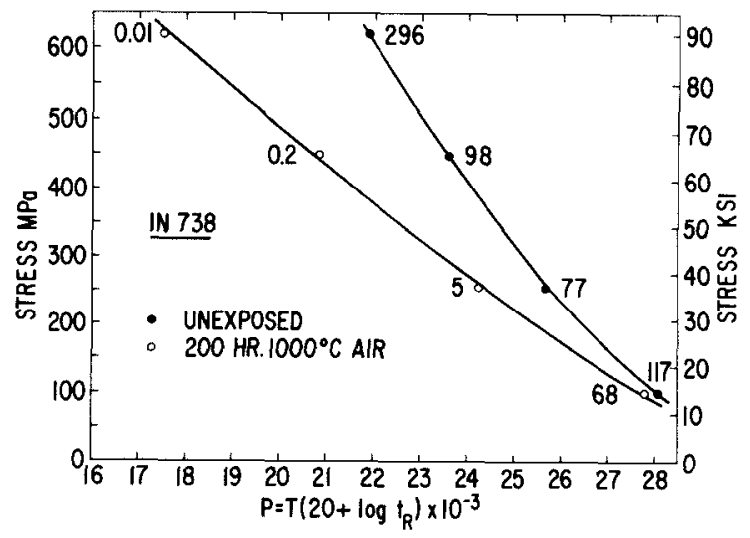

Fig. 1. Effect of Air Exposure on Rupture Life of IN738. Individual Lives are Indicated in Hours.

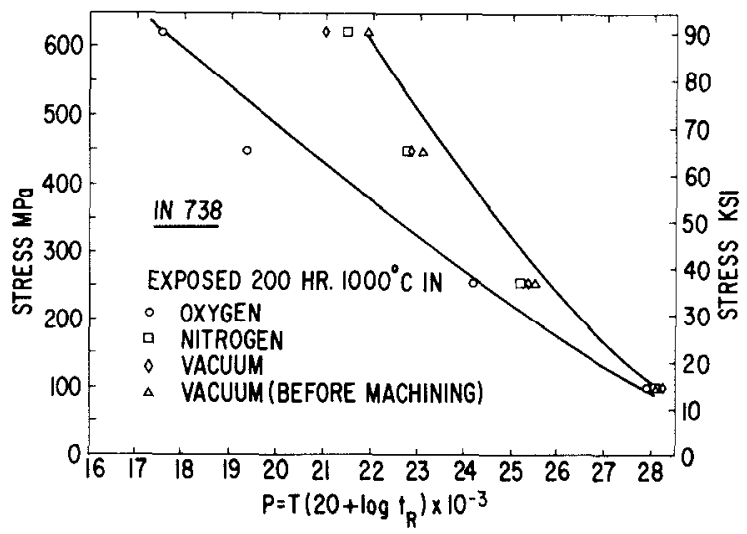

Fig. 2. Effect of Various Exposure Environments on Rupture Life of IN738. Curves are Reproduced from Fig.1. 


\section{RESULTS}

Figure 1 shows the effect of air exposure at $1000^{\circ} \mathrm{C}$ on IN738 rupture life plotted in terms of the Larson-Miller parameter. Individual lives in hours for test temperatures of $700,800,900$ and $1000^{\circ} \mathrm{C}$ are indicated. Exposures in various environments, as shown in Fig. 2, reveal that oxygen is responsible for the embrittlement. A similar damaging effect was found on air exposure of Rene'80 (Fig. 3). Reduced levels of damage result from exposure at lower temperatures, or at diminished oxygen partial pressures: examples are shown for exposure at $900^{\circ} \mathrm{C}$, and in a Ni/NiO pack. Fig. 4 shows that the loss in rupture life is reduced considerably at the high stresses, where sensitivity to the damage is greatest, when the carbon in Rene' 80 is replaced with boron. $\Lambda$ similar improvement for both boron and hafnium modified IN738 has been observed.(5)

The cobalt base alloys, FSX430 and MM509 showed no sensitivity to oxygen damage, although Fig. 5 indicates that in both cases a loss in rupture strength is associated with the thermal exposure. The oxide dispersion strengthened alloy MA754, tested in the long transverse direction, showed neither a sensitivity to the air environment nor any strength loss due to the thermal exposure (Fig. 6).

Figure 7 shows the effect on measured tensile reduction in area for Ni270. The dramatic loss in tensile ductility at intermediate temperatures after air exposure at $1000^{\circ} \mathrm{C}$ is greatly reduced for vacuum exposure and is totally eliminated if final machining follows the vacuum exposure. Thus, in this pure nickel, the tensile ductility minimum is entirely due to environmental damage. The effect of prior air exposure on ductility appears to be of the same form as that previously observed in nickel base superalloys(1-3).

\section{DISCUSSION}

The previously reported loss in tensile ductility in cast nickel base alloys is demonstrated here in pure nickel and is clearly unconnectd to any special precipitate distribution as had been suggested(2). Since the embrittlement does not occur in directionally solidified alloys $(2,6)$, it is natural to suppose that grain boundary penetration of oxygen is responsible. Although space does not allow us to present all our observations, we have direct evidence for oxygen penetration to considerable depth (damage penetration after 100 hours at $900^{\circ} \mathrm{C}$ in air is sufficient to cause a totally intergranular fracture in nickel in a gage diameter of $2.54 \mathrm{~mm}$ ). The evidence includes intergranular internal oxide in nickel doped with various solutes, and gas bubble formation at grain boundaries in nickel containing carbon (possibly due to $\mathrm{CO}$ formation). Some previous 


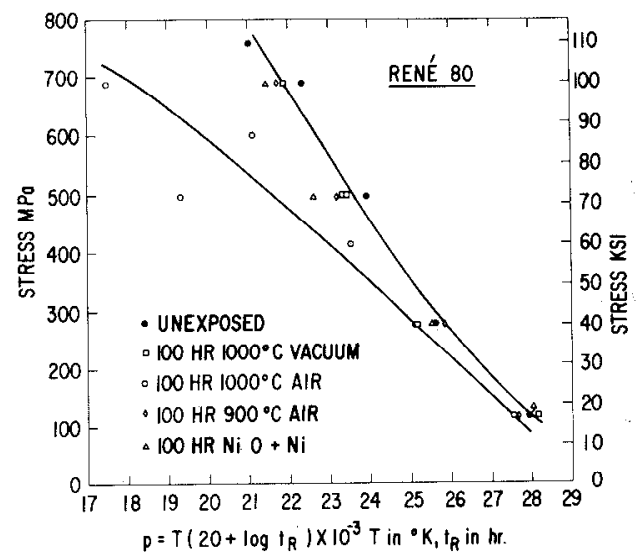

Fig. 3. Effect of Various Exposures on Rupture Life of Rene' 80.

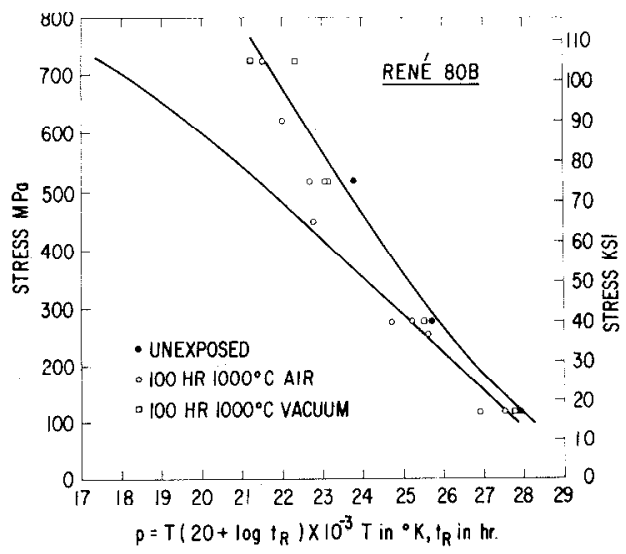

Fig. 4. Effect of Air and Vacuum Exposures on Rupture Life of Rene'80B. Curves are Reproduced from Fig. 3. 


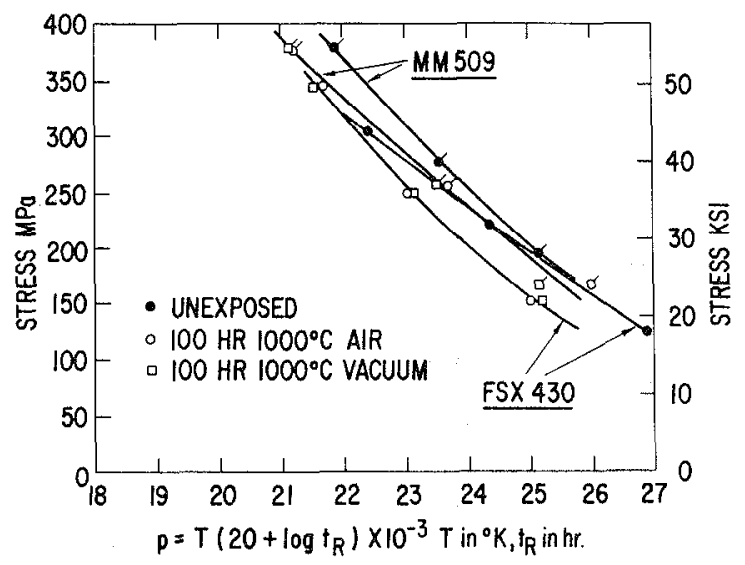

Fig.5. Effect of Air and Vacuum Exposures on Rupture Life of FSX430 and MM509.

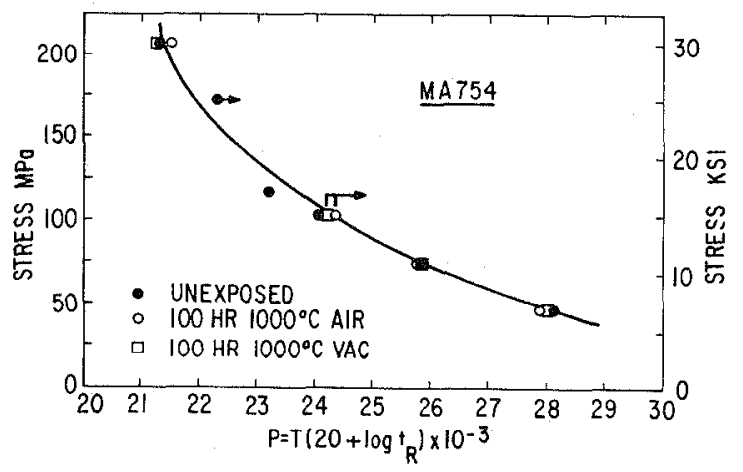

Fig. 6. Results for MA754 Showing the Insensitivity of the Alloy to Prior Exposure in Air and Vacuum. 
studies have also reported a loss in ductility and creep rupture life in nickel after prior air exposure $(7,8)$. In these studies the damage has been attributed to vacancy injection and associated internal void formation.

A clue to understanding the mechanism of embrittlement comes from the following observations on $\mathrm{Ni270}$ : at equal strain levels vacuum exposed samples recrystallize at 800 and $1000^{\circ} \mathrm{C}$, but in air exposed samples recrystallization is suppressed until $1000^{\circ} \mathrm{C}$. This reduction of grain boundary mobility after air exposures is not a novel concept, and has been previously reported in nickel(8), as well as copper(9) and silver(10,11). It is postulated to play an important role in reducing fracture resistance in the regime where grain boundary sliding becomes a significant deformation mode, and where boundary migration is needed to remove damaged regions adjacent to triple points, etc, which otherwise would lead to a lack of accomodation for the sliding and result in grain boundary fracture. This explains why little effect of prior exposure is seen at low temperatures. At the highest temperatures little effect is again displayed, as the boundaries have acquired sufficient thermal energy to overcome their pinning. Thus, the temperature dependence of the damage observed can be rationalized. Similarly, the MA754 can be regarded as intrinsically embrittled, its boundaries being already pinned by the dispersed oxide, and thus insensitive to further air exposure. Reductions in area were in fact always less than $2 \%$. The nature of the pinning has not been determined for all cases, but possibilities exist for gas pore formation, vacancy voids, internal grain boundary oxides, or solute pinning.

The reason for the apparent immunity of cobalt base alloys is not fully understood, although, in support of the general mechanism, these alloys were observed to recrystallize in regions adjacent to the fracture surface even after air exposure. Similar recrystallization has been observed in cobalt base X-40 in the vicinity of thermal fatigue cracks(12). It is not clear whether this results from a higher intrinsic boundary mobility, or from reduced oxygen penetration; this latter could result from the higher chromium content in these alloys.

The observations reported in the present paper demonstrate the specificity of gas-metal reactions. It is believed that as these studies are extended to other damaging species it will be possible to develop more accurate life prediction procedures for service in different gaseous environments. These procedures should incorporate the kinetics of the damaging process and take proper account of section size effects(6). 


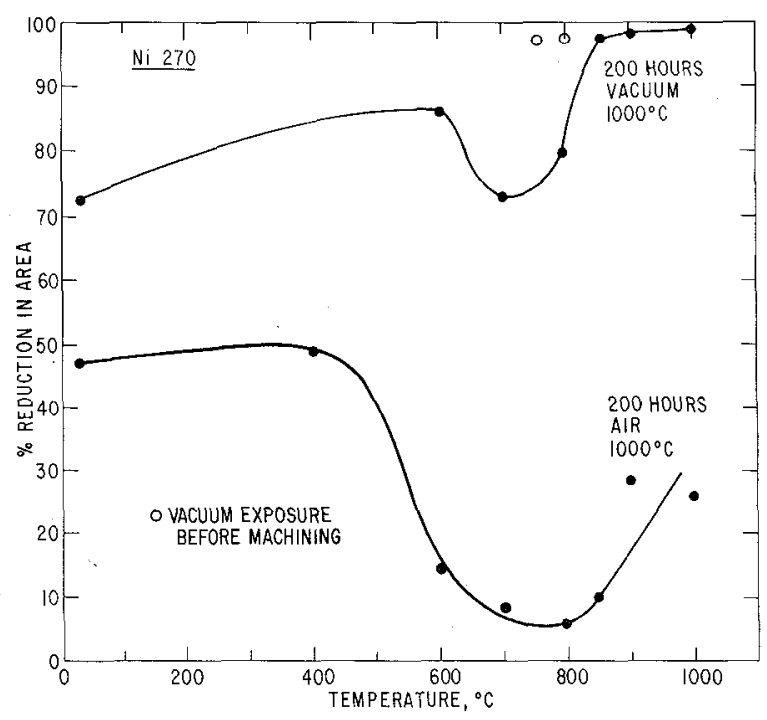

Fig.7. Intermediate Temperature Air Embrittlement of Ni270.

\section{CONCLUSIONS}

1. Pure nickel embrittles after air exposure. The tensile ductility minimum in this metal appears to be an environmental effect.

2. Cast nickel base alloys are generally sensitive to oxygen damage but their sensitivity may be reduced by chemistry modification.

3. Cast cobalt base alloys may be immune to oxygen damage but are sensitive to thermal exposure.

4. An oxide dispersion streng thened alloy, MA754, is not affected by air or vacuum exposure. It appears to be intrinsically brittle as processed.

5. The temperature dependence of the embrittlement in nickel base alloys, and the immunity of ODS alloys, can be explained in terms of a simple model involving grain boundary mobility.

Acknowledgement: Helpful discussions with J. H. Wood, D. L. Wood and D. L. Martin are gratefully acknowledged. 


\section{REFERENCES}

1) E. Ross, General Electric Company, Evendale, unpublished work, 1968.

2) W. H. Chang, "Tensile Embrittlement of Turbine Blade Alloys After High Temperature Service", Proc. Second Int. Conf. Superalloys--Processing, Seven Springs, AIME, Section V, 1972.

3) J. H. Wood, "High Temperature Tensile Embrittlement of Nickel Base Superalloys", AIME Annual Meeting, New Orleans, Feb., 1979.

4) D. A. Woodford, "The Effect of Prior Temperature Cycling on Rupture Life of Superalloys", Fourth Int. Conf. on Fracture, Waterloo, edt. D.M.R. Taplin, Vol. 2, 1977, p. 803.

5) D. A. Woodford, "Environmental Embrittlement of Nickel Base Alloys", AIME Annual Meeting, New Orleans, Feb., 1979.

6) D. A. Woodford, "An Assessment of the Role of Test Environment in Creep Rupture Life Prediction", Int. Conf. on Engineering Aspects of Creep, Sheffield, Sept., 1980.

7) D. L. Douglass, "The Effect of Oxidation on the Mechanical Behavior of Nickel at $600^{\circ} \mathrm{C}$, Mat. Sci. Eng., Vol. 3, 1968/69, p. 255.

8) P. Hancock, "Influence of Vacancies Produced by Oxidation on the Mechanical Properties of Nickel and Nickel-Chromium Alloys", Vacancies '76, The Metals Society, 1976, p. 215.

9) D. L. Wood, "Effect of Dissolved Oxygen on the Grain Size of Annealed Pure Copper and Cu-Al Alloys", Journ. Metals, Vol. 9, 1957, p. 406.

10) D. L. Martin and E. R. Parker, "Embrittlement of Silver by Oxygen and Hydrogen", Trans. AIME, Vol. 152, 1943, p. 269.

11) J. C. Chaston, "Some Effects of Oxygen in Silver and Silver Alloys", J. Inst. Metals, Vol. 71, 1945, p. 23.

12) D. A. Woodford, "Thermal Fatigue of Gas Turbine Materials", ICM 3, Cambridge, England, Vol. 2, 1979, p. 33. 